El principio de subsidiariedad y su papel en la determinación de las competencias sancionatorias de la Unión Europea. Relación con el principio de complementariedad de la Corte Penal Internacional.

\title{
EL PRINCIPIO DE SUBSIDIARIEDAD Y SU PAPEL EN LA DETERMINACIÓN DE LAS COMPETENCIAS SANCIONATORIAS DE LA UNIÓN EUROPEA. RELACIÓN CON EL PRINCIPIO DE COMPLEMENTARIEDAD DE LA CORTE PENAL INTERNACIONAL*
}

Raúl Carnevali R.**

\section{Cuestiones preliminares}

Si bien la Corte Penal Internacional y la Unión Europea conforman estructuras organizativas que persiguen fines distintos, sí puede decirse que comparten ciertos presupuestos axiológicos comunes que explicarían su creación y posterior desarrollo, y que dicen relación con el reconocimiento y protección de los derechos fundamentales. Asimismo, ambas tienen como hecho histórico vinculante la Segunda Guerra Mundial. En efecto, en el caso de la Unión Europea, si bien con anterioridad al año 1939 hubo propuestas hacia la integración ${ }^{1}$, el camino definitivo comenzó a transitarse tras la última conflagración. Particularmente suele señalarse

* Este Trabajo ha sido realizado dentro del marco del Proyecto Fondecyt N 1080060 titulado "El Principio de complementariedad: un cambio de paradigma en la justicia internacional”. Una versión preliminar se presentó como ponencia en la Conferencia "La relación entre la Corte Penal Internacional y los Estados. El Principio de complementariedad", organizada por la Universidad de Chile el día 5 de marzo de 2009.

** Doctor en Derecho. Profesor Asociado de Derecho Penal y Subdirector del Centro de Estudios de Derecho Penal de la Universidad de Talca. Correo electrónico: rcarnevali@utalca.cl

1 Para Europa la Primera Guerra Mundial dejó como enseñanza que la división sólo la llevaría a desarrollar un papel menor en el concierto mundial, como asimismo ser fuente continua de conflictos. Por ello el Conde Coundenhove-Kalergi propuso la formación de los Estados Unidos de Europa. Por otra parte, el Ministro francés Briand planteó en 1929, en el seno de la Sociedad de Naciones, la necesidad de crear una Unión Europea. De esta forma el propósito integrador dejó de desarrollarse en el plano meramente teórico, para dirigirse a uno práctico, el que luego sería retomado tras finalizar la Segunda Guerra. En todo caso, con anterioridad pueden mencionarse los trabajos de Kant con su obra La pazperpetua, Montesquieu, Saint-Pierre o Saint-Simon, quienes también formularon ideas dirigidas a una integración. Cfr. Truyol y Serra, Antonio. La integración europea. Idea y realidad. Madrid, 1972, p. 18 y ss.; Béroud, Sophie/Weydert, Jean, Le devenir de l'Europe. Paris, 1997, p. 41-46; Sainte Lorette, Lucien de, La integración europea. Barcelona, 1957, p. 23-24. 
como punto inicial el discurso pronunciado por Churchill en Zurich en $1946^{2}$. No cabe duda que el éxito del proceso integrador europeo radica en que los países que la conforman comparten un horizonte valorativo común, aunque coexistan diversas realidades culturales _como afirma Morin Europa es una unitas multiplex ${ }^{3}$. En este sentido, la construcción del sistema comunitario se apoya en el reconocimiento de los derechos fundamentales y libertades públicas, tal como se aprecia en el Art. 6 del Tratado de la Unión Europea ${ }^{4}$. Este consenso valorativo mínimo expresado en el Tratado pone de manifiesto, por una parte, la vocación democrática y de respeto a los derechos fundamentales que inspiran a los Estados miembros _además, todos forman parte del Consejo de Europa_ y por la otra, la exigencia que deben alcanzar quienes pretenden integrar la Unión ${ }^{5}$.

En lo que respecta a la Corte Penal Internacional también puede decirse que la Segunda Guerra Mundial y sus trágicas consecuencias constituye el paso fundamental hacia su conformación. Si bien es cierto, debieron pasar más de cincuenta años para llegar al Estatuto de Roma, fueron los juicios de Nuremberg los que resultaron determinantes acerca de la necesidad de instaurar una corte internacional que juzgue crímenes internacionales ${ }^{6}$. Precisamente, a través de la resolución número 177 (II) de 21 de noviembre de $1947^{7}$, la

2 Truyol y Serra, La integración, cit. nota n. 1, p. 31. En p. 92-95 se reproduce su discurso. También en http:// www.coe.int/T/E/Com/About Coe/DiscoursChurchill.asp (consultado el 21 de enero de 2009).

Morin, Edgar, Pensar Europa. La metamorfosis de Europa. (trad. B. Anastasi de Lonné), 2 a ed., Barcelona, 1994, p. 63, señala que son las fuentes judías, cristianas, griegas y latinas las que han confluido para formar una síntesis armoniosa que constituyen el substrato específico y el común denominador cultural de Europa.

4 "Artículo 6: 1. La Unión se basa en los principios de libertad, democracia, respeto de los derechos humanos y de las libertades fundamentales y el Estado de Derecho, principios que son comunes a los Estados miembros.

2. La Unión respetará los derechos fundamentales tal y como se garantizan en el Convenio Europeo para la Protección de los Derechos Humanos y de las Libertades Fundamentales firmado en Roma el 4 de noviembre de 1950, y tal y como resultan de las tradiciones constitucionales comunes a los Estados miembros como principios generales del Derecho comunitario.

3. La Unión respetará la identidad nacional de sus Estados miembros.

4. La Unión se dotará de los medios necesarios para alcanzar sus objetivos y para llevar a cabo sus políticas". Así también se reconoce en el proyecto Tratado por el que se establece una Constitución Europea, parte II. En: http://eur-lex.europa.eu/JOHtml.do?uri=OJ:C:2004:310:SOM:ES:HTML (consultado el 21 de enero de 2009). Granado Hijelmo, Ignacio, "Constitución europea y jurisprudencia de sistemas", en Revista de Estudios Europeos. № 9, 1995, p. 41, señala que desde 1964 el Parlamento Europeo ha hecho suyo el informe Birkelback, que estableció como doctrina política de admisión a la Comunidad Europea la exclusión de aquellos Estados cuyos gobiernos carecen de legitimidad democrática y cuyos pueblos no participan en las decisiones del gobierno.

$6 \quad$ En todo caso, después de la Primera Guerra Mundial se comenzó a trabajar en un Estatuto para juzgar crímenes de orden internacional. El propio Tratado de Versalles, en el Art. 227, ordenó el establecimiento de un Tribunal para juzgar al Kaiser Guillermo II. Cfr. Cassese, Antonio, International Criminal Law. ${ }^{\circ}$ ed., New York, 2008, p. 27-31; Schabas, William, An Introdution to the International Criminal Court. $3^{\circ}$ ed. New York, 2007, p. 3; Carnevali Rodríguez, Raúl, "Hacia la conformación de un Tribunal penal internacional. Evolución histórica y desafíos futuros", en Revista de Derecho de la Universidad Católica del Norte. Sede Coquimbo. N 10, 2003, p. 32 y ss.

7 Resolución número 177 (II) de 21 de noviembre de 1947 en http://daccessdds.un.org/doc/RESOLUTION/GEN/ NR0/038/84/IMG/NR003884.pdf?OpenElement (consultado el 21 de enero de 2009). 
El principio de subsidiariedad y su papel en la determinación de las competencias sancionatorias de la Unión Europea. Relación con el principio de complementariedad de la Corte Penal Internacional.

Asamblea General de las Naciones Unidas encomendó a la Comisión de Derecho Internacional que "formulase los principios del derecho internacional reconocidos en la Carta de los Juicios de Nuremberg y en las determinaciones del tribunal"s.

Asimismo, en cuanto a la finalidad tuitiva que explicaría la instauración de la Corte Penal Internacional guarda relación con la persecución de determinados crímenes violatorios de los derechos fundamentales, lo que no lo transforma, por cierto, en un Tribunal de Derechos Humanos. En efecto, en su aspecto más esencial y básico todo lo que representa la Corte y en general, los sistemas de imputación penal internacional buscan evitar la impunidad_como se desprende del preámbulo del Estatuto de Roma_de todos aquellos actos individuales que representan los mayores atentados a los derechos humanos ${ }^{9}$. Ello explicaría el establecimiento del principio de complementariedad, es decir, si un Estado no desea o no puede juzgar, resulta legítima la intervención de una instancia internacional. En este sentido, cuando se valora la justicia internacional y su proyección, debe hacerse desde otra perspectiva: que ésta encuentra su basamento axiológico en las legítimas aspiraciones de la comunidad de que se respeten sus Derechos Fundamentales, los que están por sobre los también legítimos propósitos de un Estado de actuar soberanamente y sin interferencias. Esto es, ante un posible conflicto de intereses, derivado de la posible impunidad, debieran primar aquéllas. Es importante tener en cuenta los cambios que en la esfera valorativa se están produciendo, hoy ya no resultan tolerables determinados comportamientos. Existen mínimos que nacen del concepto de persona, de su dignidad y sus Derechos Fundamentales, cuya protección es un imperativo. Que sea una Corte de carácter internacional la que resuelva conflictos que repercutirán en un territorio determinado, no es argumento suficiente para inhibir la actuación de aquélla. Primeramente, debe tenerse presente que su intervención tiene lugar respecto de delitos estimados crimina juris gentium, es decir, actos de tal significación y trascendencia que afectan a la humanidad toda.

Lo recién expuesto permite ir centrando el tema principal de este trabajo, a saber, de qué forma ambas instituciones se relacionan con los Estados nacionales. Y es que ninguna de ellas pretende prescindir de la importante función que a éstos les cabe, tanto en el logro integracionista como en la persecución de los crímenes internacionales. Sin embargo, es ineludible delimitar el campo de acción de las instituciones nacionales e internacionales. Para ello, los respectivos tratados se encargan de indicar cuándo y bajo qué circunstancias pueden o deben actuar los Estados.

Los principios elaborados por la Comisión de Derecho Internacional en 1950 se pueden encontrar en http:// untreaty.un.org/ilc/texts/instruments/english/draft\%20articles/7_1_1950.pdf (consultado el 21 de enero de 2009).

9 En estos términos, Ambos, Kai, La parte general del Derecho Penal Internacional. (trad. E. Malarino), Montevideo, 2005, p. 33. 
Es así, que tratándose de la Unión Europea resulta esencial el llamado principio de subsidiariedad, como lo es para la Corte Penal, el principio de complementariedad. Ahora bien, la determinación de ambos principios no es tarea fácil, pues como bien señala Miskowiak, son nociones particularmente ambiguas ${ }^{10}$.

Además, debe tenerse presente lo que está en juego es precisar el ejercicio del ius puniendi. Para las sensibilidades nacionales resulta especialmente incómoda la intervención, dentro de su territorio, de normas e instituciones ajenas, más aún si tienen repercusiones punitivas. Y es que el símbolo de poder que representa el Derecho Penal para un Estado es muy fuerte y conforman una de las expresiones más evidentes del ejercicio de la soberanía ${ }^{11}$.

Considerando que los principios recién mencionados comparten una similar misión, a saber, disponer de criterios para precisar ámbitos competenciales, es imprescindible aportar luces acerca de sus contornos. Este examen permitirá a su vez, clarificar qué comparten y en qué se distinguen ambos principios.

Mi atención se dirigirá de manera particular al principio de subsidiariedad, para luego referirme al principio de complementariedad. Para este efecto, analizaré primeramente la naturaleza jurídico- política de la Unión Europea a fin de precisar cuál es el rol que al respecto le corresponden a los Estados miembros, especialmente en la determinación de las competencias. Hago presente desde ya, que mi acercamiento al principio de complementariedad no será exhaustivo y sólo se referirá a aquellos puntos que son de interés para este estudio.

\section{Naturaleza jurídico-política de la Unión Europea ${ }^{12}$}

Para poder precisar su carácter es necesario efectuar algunas precisiones que permitan comprender la naturaleza de sus funciones. Por de pronto, la Unión Europea y las instituciones que la conforman no responden, en estricto rigor, a organismos de índole intergubernamental, sino más bien obedecen a otra tipología de organización política. En efecto, aun cuando las

10 Miskowiak, Kristina, The International Criminal Court: Consent, Complementarity and Cooperation. Copenhagen, 2000, p. 39.

11 Carnevali Rodríguez, Raúl, Derecho penal y Derecho sancionador de la Unión Europea. Granada, 2001, p. 253; Bacigalupo, Silvina, "Derecho penal y construcción europea”, en Bacigalupo, Silvina/Cancio Meliá, Manuel, Derecho penal y política transnacional. Barcelona, 2005, p. 142, hace notar que el Derecho Penal juega un papel simbólico significativo en la construcción europea, pues no pocos ven en la competencia penal de la Unión un paso decisivo hacia la Federación y con una pérdida de la identidad nacional. Sobre la construcción de un Derecho Penal europeo de corte federal, Gómez-Jara Díez, Carlos, "Constitución europea y Derecho penal: ¿hacia un Derecho penal federal europeo?”, en Bacigalupo, Silvina/Cancio Meliá, Manuel, Derecho penal y política transnacional. Barcelona, 2005, p. 153 y ss.

12 Las materias examinadas en los títulos 2, 3 y 4 constituyen una actualización de lo expuesto en mi libro Derecho penal y Derecho sancionador de la Unión Europea. Granada, 2001. 
El principio de subsidiariedad y su papel en la determinación de las competencias sancionatorias de la Unión Europea. Relación con el principio de complementariedad de la Corte Penal Internacional.

Comunidades Europeas se conformaron a través de tratados internacionales, éstas no responden a las características que son propias a las de una organización internacional ${ }^{13}$. Por el contrario, dada la autonomía de que gozan las instituciones comunitarias frente a las autoridades nacionales y las características de su ordenamiento jurídico, hay quienes se inclinan por estimarla más cercana a una estructura de corte federal ${ }^{14}$. Empero, tampoco puede responder a una organización política de este orden, pues carece de una de sus facultades más representativas, a saber, las competencias originarias (Kompetenz-Kompetenz $)^{15}$. En efecto, las Comunidades Europeas sólo estarían, en principio, dotadas de aquellas competencias que los Estados les han cedido, las llamadas competencias de atribución ${ }^{16}$.

Conforme a lo anterior, que las Comunidades no se comprendan como organizaciones intergubernamentales ni tampoco a una de orden federal, es que se habla para su encuadramiento dentro de una organización jurídico-política de supranacionalidad ${ }^{17}$. Concepto éste en el que se enmarcan las organizaciones de integración - como lo son efectivamente las Comunidades, y que se distinguen de las de cooperación, que se comprenden en la internacionalidad —Así, Consejo de Europa, Naciones Unidas-, es decir, instituciones internacionales en su sentido clásico. Estas últimas, se caracterizan principalmente, porque los Estados que la conforman no ven alteradas sus competencias, éstas se mantienen dentro de su esfera de acción, ya que se organizan interestatalmente para contribuir al logro de determinados fines. Es decir, sus soberanías no se ven particularmente limitadas.

13 En este sentido, puede tenerse en consideración la relación que existe entre las normas comunitarias y las naciones. Así, la aplicación del principio de primacía y de efecto directo. Cfr. Carnevali Rodríguez, Raúl, "Relación entre el Derecho comunitario europeo y los Derechos nacionales de los Estados miembros", en Temas de Derecho, Universidad Gabriela Mistral, año XIII, N 1 y 2, 1998, p. 165 y ss.

14 Entre otros, Mangas Martín, Araceli, Prólogo de Tratado de la Unión Europea y Tratados Constitutivos de las Comunidades Europeas, Ed. Tecnos, Madrid, 1995, p. 23, quien afirma que la vocación federal de la Unión Europea es más que visible en los objetivos del art. B del Tratado de la Unión (hoy art. 2); Molina del Pozo, Carlos, Manual de Derecho de la Comunidad Europea. $3^{\mathrm{a}}$ ed. Madrid, 1997, p. 132; En sentido contrario, Martínez López-Muniz, José Luis, ¿Qué Unión Europea?, en Papeles de la Fundación, No 34, Madrid, 1996, p. 19 y ss, quien estima que se está ante una unión de Estados soberanos, lejos de toda posibilidad federalista. Es más, para este autor sería un error que la Unión Europea se demarcara por este modelo político.

15 Ippolito, Francesca. Fondamento, attuazione e controllo del principio di sussidiarietà nel diritto della Comunità e dell'Unione Europea. Milano, 2007, p. 62.

16 Ipsen, Hans Peter, Europäisches Gemeinschaftsrecht. Tübingen, 1972, p. 189, 193, 196-200, después de analizar porqué las Comunidades Europeas no son ni un Estado Federal ni sólo organizaciones internacionales, señala que éstas hay que comprenderlas dentro del concepto de integración funcional con fines determinados (Zweckverbände funktioneller Integration), por cuanto los Estados se han integrado en una Comunidad con competencias propias (no originarias) a fin de cumplir determinados objetivos, principalmente de orden económico.

17 Pescatore, Pierre, The law of integration. Leiden, 1974, p. 49 y ss, al explicar el significado de la supranacionalidad, señala que en él es posible reconocer tres particularidades, a saber: la presencia de valores comunes de quienes participan, la creación de un poder efectivo al servicio de estos intereses comunes y que este poder sea autónomo. Estas características permitirían distinguir lo que es supranacional de lo internacional. En esta última esfera, agrega, muchas veces no es posible encontrar ni el primero de los elementos mencionados; Molina del Pozo, Manual de Derecho, cit. nota n. 14, p. 134, quien aporta abundante bibliografía sobre este concepto. 
Raúl Carnevali R.

Al respecto, no es aventurado afirmar que los objetivos que se han alcanzado a través del proceso europeo, difícilmente se habrían obtenido de haberse seguido un camino de corte internacional. Hay que tener presente que ya existían organizaciones internacionales con anterioridad, ya sea el Consejo de Europa o la OECE (Organización Europea para la Cooperación Económica) hoy OCDE (Organización para la Cooperación y Desarrollo Económico). Sin embargo, los padres fundadores estimaron que si lo que se pretendía era lograr una unidad, que pudiera llegar en un futuro a una integración política, era necesario conformar otro tipo de organización, con mayores poderes y organicidad. Cualidades éstas difíciles de hallar en organizaciones de carácter intergubernamental, cuyas decisiones muchas veces tienen escasa repercusión por la exigua "cooperación" de sus miembros. Es por ello, que el proceso de integración que ha desarrollado Europa — que supone la escala superior de organización entre Estados, por lo menos en lo que se conoce hasta ahora ${ }^{18}$ - lleva consigo una mayor limitación en la actuación soberana de los Estados, pues se dota a la organización de organismos autónomos con poderes propios $^{19}$. Puede decirse que la integración, aun cuando suponga una limitación de decisiones soberanas, el Estado no los pierde sino que acepta que otros organismos decidan con é $l^{20}$.

18 En los procesos de integración también existe una escala tipológica, conforme a los objetivos que se persiguen. Así, la primera escala integradora está constituida por la conformación de una zona de libre comercio, en la cual se eliminan trabas al comercio de los productos de los países que participan en dicha zona. Fundamentalmente, supone establecer una libre circulación de las mercancías originarias de los países que la conforman, pero, cada uno puede establecer sus propias políticas respecto de productos provenientes de terceros Estados. Con la organización de una unión aduanera se estructura la segunda escala, en la que se establece una tarifa externa común para todo el territorio, respecto a productos provenientes de terceros países, independiente del Estado de la unión por la que ingrese. La implantación de un mercado común, supone entrar en la tercera fase integradora. Ella implica eliminar todas aquellas medidas que obstaculicen la libre circulación, no sólo de mercancías, sino además, de personas, capitales y servicios, es decir, liberalizar todos los factores productivos. Por último, con la implantación de la unión económica y monetaria se logra la máxima integración económica, con la unificación de las políticas económicas. Al respecto, Behrens, Peter, "Integrationstheorie. Internationale wirtschaftliche Integration als Gegenstand politologischer, ökonomischer und juristischer Forschung", en Rabels Zeitschrift, 1981, p. 27 y ss.

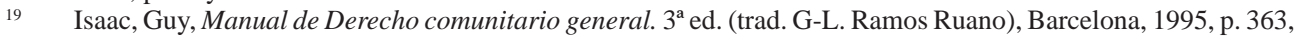
habla de un poder público común, independiente de los Estados, pero no "extranjero", pues las competencias son ejercidas en común. La reducción competencial por los Estados no debe ser vista como una pérdida, sino como una mutación en el ejercicio de éstas, por cuanto las decisiones ahora se adoptan en común.

20 Para Molina del Pozo, Manual de Derecho, cit. nota n. 14, p. 135-136 la integración se manifiesta con los siguientes rasgos: "1) la organización ejerce poderes propios del mismo tipo que los que resultan de las funciones superiores de Estado; 2) en los órganos formados por representantes de los Estados, las deliberaciones pueden realizarse según las reglas de la mayoría; 3) los órganos están formados por personas que no son representantes de los Estados y que, sin embargo, participan de decisión; 4) los poderes de la organización se ejercen inmediatamente, sin pasar por el filtro que suponen los gobiernos nacionales en beneficio o en contra de los particulares, lo que significa que pueden modificar directamente los ordenamientos jurídico nacionales, y 5) finalmente, estas organizaciones se encuentran sometidas a un orden jurídico muy desarrollado, cuya salvaguardia es preciso confiarla a un Tribunal de Justicia”. 
El principio de subsidiariedad y su papel en la determinación de las competencias sancionatorias de la Unión Europea. Relación con el principio de complementariedad de la Corte Penal Internacional.

Conforme a lo expuesto, puede afirmarse que el modelo configurativo de orden político adoptado por la Unión Europea es, por una parte, el de una organización de integración de carácter funcional - las dos comunidades - y por otro, de cooperación — conforme a lo dispuesto en los títulos V y VI del Tratado de la Unión Europea- ${ }^{21}$. Como organización de integración, —cuyo ejemplo más representativo es la Comunidad Europea- los Estados miembros han transferido a ésta algunas de sus competencias, de manera que ya no tienen el ejercicio pleno en la determinación de aquéllas. Es el ente supranacional el llamado a ejercerlas. En cambio, en políticas de cooperación, las relaciones de los Estados miembros se mueven más bien en el plano intergubernamental, esto es, manteniendo sus soberanías, coordinándose para un determinado fin. Así sucede, por ejemplo, con el título VI que comprende materias de cooperación policial y judicial en materia penal. En todo caso, a diferencia de los tratados anteriores, el de Niza ha supuesto, conforme se aprecia en el Art. 34 del Tratado, el establecimiento de ciertos mecanismos de mayor flexibilidad en la adopción de acuerdos.

Tal como se destacó precedentemente, las Comunidades Europeas son una organización que goza de competencias de atribución ${ }^{22}$. En términos generales, quiere significar que sólo pueden actuar para la consecución de determinados fines, en la medida que así lo hayan dispuesto los Estados miembros. Sobre este punto, es muy importante tener presente que los Tratados constitutivos no atribuyen materias, sino objetivos a lograr ${ }^{23}$. Conforme con la orientación funcionalista que identifican a las Comunidades desde su fundación, éstas se dirigen a cumplir aquellas funciones que les permitan alcanzar los objetivos propuestos ${ }^{24}$. Por lo demás, así se desprende del art. 5 del Tratado de la Comunidad Europea, al indicar que ésta debe actuar "dentro de los límites de las competencias que le atribuye el presente Tratado y de los objetivos que éste le asigna". En todo caso, cada decisión adoptada por las instituciones comunitarias debe fundamentarse, directa o indirectamente, en una o más disposiciones específicas de los Tratados ${ }^{25}$.

Lo que se acaba de exponer es una característica esencial y muy particular de las

El art. 1 del Tratado señala: "La Unión tiene su fundamento en las Comunidades Europeas completadas con las políticas y formas de cooperación establecidas por el presente Tratado".

López Castillo, Ángel, Constitución e integración. Madrid, 1996, passim, se pronuncia sobre la naturaleza jurídica de la atribución-cesión de competencias a entidades supranacionales y la problemática que desde una perspectiva constitucional supone la integración, sobre todo la experiencia alemana y española. Ippolito, Fondamento, cit. nota n. 15, p. 68 y ss.

Molina del Pozo, Manual de Derecho, cit. nota n. 14, p. 148-149, señala que la técnica empleada obedece a criterios funcionales o teleológicos y no a consideraciones materiales, como es lo usual en este tipo de habilitaciones. Además agrega, "La competencia no se cede a una Comunidad 'en' cierta materia, digamos transporte o legislación aduanera, sino que se residencia en sede comunitaria 'para' desempeñar una función o conseguir un fin, ya sean éstos la implantación de una política común de los transportes o la eliminación de las trabas a la libertad de circulación de personas, bienes y capitales".

Barents, René, "The internal market unlimited: some observations on the legal basis of community legislation", en Common Market Law Review, 1993, p. 85. 
Comunidades, como organizaciones de integración. Y es que el empleo de un método de atribución funcional de competencias puede llevar a que su potestad normativa comprenda considerables ámbitos. En efecto, si bien conforme al art. 5, a la Comunidad Europea no se le confiere competencias ilimitadas sino las indicadas en los art 3 y 4 para la consecución de los fines del art. 2, no pocas no se encuentran bien precisadas en el resto del articulado del Tratado —en las que se concretan las acciones previstas ${ }^{26}$.

Por tanto, al estar los márgenes que fijan el dominio funcional más bien indeterminados, nada impediría que para desarrollar las acciones comunitarias, tenga lugar una interpretación extensiva, si con ello se logran los fines para los cuales se constituyó la Comunidad Europea $^{27}$. Considerando, por un parte, los fines que se precisan en el art. 2 y por la otra, que las competencias atribuidas para tal propósito no resultan del todo determinadas, se ha generado, efectivamente — conforme al método funcionalista empleado—, una extensión de éstas en favor de la Comunidad.

En este sentido, desempeñan, entre otras, una importante función las disposiciones relativas a la aproximación de legislaciones_Art. 94 y ss. del Tratado de la Comunidad Europea_, como asimismo el art. 308, pues han permitido superar ciertas barreras que en materia de atribución competencial puedan presentar los Tratados, erigiéndose en importantes preceptos fundamentadores de la actuación comunitaria ${ }^{28}$. En efecto, éstos, en términos generales, se refieren a la aproximación de legislaciones que dicen relación con el establecimiento y el funcionamiento del mercado común y de una unión económica y monetaria. Pues bien, teniendo presente que el concepto de mercado común es un término amplio, de difícil delimitación, no sólo comprensivo de aspectos económicos sino también abarca esferas de contenido social, no llama la atención su recurso para contener nuevos ámbitos, si con ello autoriza el desarrollo del mercado común que es uno de los objetivos de la Comunidad.

El que no exista un reparto competencial claro y que las atribuciones de la Comunidad Europea se hayan configurado de conformidad al binomio medios disponibles-objetivos (fines) a alcanzar ha generado algunas dificultades en la determinación de si tal materia sigue formando parte de la esfera estatal o, por el contrario, es la Comunidad la que debe normar. Es cierto que puede partirse de la premisa de que las competencias no atribuidas a la Comunidad Europea permanecen dentro del ámbito estatal. Empero, teniendo en consideración lo expuesto, a saber,

\footnotetext{
26 Barents, "The internal market", cit. nota n. 25, p. 88-89, resalta que la formulación general de estas competencias es la inevitable consecuencia de los objetivos del Tratado, que al ser tan amplios no pueden llevarse a cabo sin la atribución de poderes discrecionales. Ello sería el reflejo de ser el Tratado de la Comunidad Europea un "Tratado-marco".

27 En estos términos, Molina del Pozo, Manual de Derecho, cit. nota n. 14, p. 149; para Isaac, Manual, cit. nota n. 19 , p. 46, el método funcional puede generar una competencia normativa ilimitada. Ippolito, Fondamento, cit. nota n. 15, p. 93 y ss.
} 
El principio de subsidiariedad y su papel en la determinación de las competencias sancionatorias de la Unión Europea. Relación con el principio de complementariedad de la Corte Penal Internacional.

que el propósito del proceso europeo se construye conforme a una integración progresiva, autoriza que las fronteras competenciales sean difusas, obligando al Tribunal de Justicia de las Comunidades a precisar la titularidad de éstas.

Conforme a lo expuesto, es posible realizar la siguiente distinción: lo que son competencias exclusivas y las competencias compartidas ${ }^{29}$. Respecto a las primeras, se caracterizan porque se excluye toda intervención nacional, quedando determinadas áreas sólo dentro de la esfera de actuación de la Comunidad. Allí pueden comprenderse, tanto la supresión de los obstáculos a la libre circulación de las cuatro libertades comunitarias -libre circulación de mercancías, capitales, personas y servicios- y las normas generales sobre competencia, como también, la de algunos sectores englobados dentro las políticas comunes, a saber, el comercial, agrícola, pesquero o de transportes ${ }^{30}$. Precisamente, dado el carácter funcional del proceso integrador, esta esfera competencial no puede entenderse como estática. Por el contrario, está en constante evolución, dependiendo de los avances en el proceso integracionista. Por de pronto, en su momento las políticas monetarias, sobre todo cuando tuvo lugar la última fase de la Unión Económica y Monetaria -antes de la entrada del euro- comenzaron a formar parte de las competencias exclusivas $^{31}$.

No obstante, la regla general es que las competencias sean compartidas, ya que ambos, Estados miembros y Comunidades están facultados a ejercer sus atribuciones en aquellos ámbitos que forman parte de tales competencias. Lo anterior no significa que, tanto los Estados miembros como la Comunidad ejerciten "simultáneamente" tales competencias, sino que, ambos están llamados a realizarlas. Sin embargo, como se puede desprender de lo expuesto, en la medida que la Comunidad asuma efectivamente el ejercicio de tales competencias las irá despojando de su carácter nacional ${ }^{32}$.

Como señala Isaac, ésta es la única solución posible para evitar el vacío jurídico que se puede producir ante la carencia de una presencia normativa por parte de la Comunidad. Por otro lado, ante la imposibilidad de que en el ámbito comunitario se pudieran adoptar todas las

Así, la Comisión en una Comunicación al Consejo y al Parlamento Europeo de 27 de octubre de 1992, publicada en Comisión de las Comunidades Europeas, Boletín de las Comunidades Europeas, no 10, Bruxelles, 1992, p. 122-123, señala que la noción de competencia exclusiva se desarrolló por la obligación de realizar el mercado común. A partir de esta exigencia, se ha ido constituyendo, a través de la jurisprudencia del Tribunal de Justicia de las Comunidades, el bloque de las competencias exclusivas, organizado en torno a las cuatro libertades fundamentales y a determinadas políticas comunes indispensables para el establecimiento del mercado interior.

30 Comisión de las Comunidades Europeas, Boletín de las Comunidades Europeas., nº 10, Bruxelles, 1992, p. 123; Ippolito, Fondamento, cit. nota n. 15, p. 74 y ss.

31 Debe tenerse presente, que la inactividad comunitaria en ningún caso significa una restitución de las competencias a los Estados miembros. Así, Sentencia del Tribunal de Justicia de las Comunidades Europeas (TJCE) Comisión c. Reino Unido de 10 de julio de 1980, asunto 32/79, Recopilación 1980-3. 
medidas necesarias para llevar a cabo la integración —en cuyo caso se generaría una paralización peligrosa-, se estima imprescindible que la transferencia competencial se haga de manera paulatina, de tal forma que se asegure una adecuada presencia normativa en todos los sectores, permitiendo así, que la Comunidad vaya asumiendo sus funciones conforme progrese la integración $^{33}$.

Sin embargo, considerando la naturaleza funcional de las competencias de que está dotada la Comunidad, existe el riesgo de que una inadecuada interpretación de cuál debe ser su esfera de acción, pueda significar una ampliación excesiva de sus intervenciones, que lleve consigo una reducción - peligrosa - de las que corresponden a los Estados miembros. En efecto, dicho peligro se puede manifestar desde dos perspectivas: por un lado, generar en los Estados, ante la creciente actividad de la Comunidad, un cierto recelo que los desaliente a otorgar nuevas atribuciones, y por otro, que al desaprovecharse la actuación estatal, los fines que se pretenden alcanzar, se desarrollen de manera disfuncional.

Por lo anterior, es que surge la necesidad de disponer de un sistema que permita regular el ejercicio competencial, el que no debe confundirse con reglas de determinación de la titularidad o de atribución de éstas ${ }^{34}$. Precisamente, esto es lo que motiva la consagración del principio de subsidiariedad, regulado en el art. 5 del Tratado de la Comunidad Europea, al igual que el principio de proporcionalidad, aunque, claro está, entre ambos existen importantes diferencias. Por de pronto, el art. 5, al referirse al principio de subsidiariedad, establece que éste podrá invocarse en aquellos ámbitos que no sean de competencia exclusiva de la Comunidad. En cambio, tratándose del principio de proporcionalidad - inciso final del art. 5- al no hacer tal distinción, puede invocarse, tanto para las competencias exclusivas como para las compartidas.

\section{El principio de subsidiariedad en la Unión Europea}

Este se halla expresamente mencionado como principio general en el art. 2 del Tratado de la Unión Europea, como asimismo en el art. 5 del Tratado de la Comunidad Europea ${ }^{35}$. Como ya se indicó, el principio en cuestión no tiene por objeto atribuir competencias sino regular el

Isaac, Manual, cit. nota n. 19, p. 51; Molina del Pozo, Manual de Derecho, cit. nota n. 14, p. 156. Ippolito, Fondamento, cit. nota n. 15, p. 48 y ss.; Barnés Vázquez, Javier, "El principio de subsidiariedad y las regiones europeas. Las Comunidades Autónomas”, en Barnés Vázquez, Javier (Coor.), La Comunidad Europea, la instancia regional y la organización administrativa de los Estados miembros. Madrid, 1993, p. 541.

35 Acerca de su origen y su manifestación en la doctrina social de la Iglesia, cfr. Boixareu Carrera, Ángel, "El principio de subsidiariedad", en Revista de Instituciones Europeas, 1994, p. 773, quien además indica abundante bibliografía; Cass, Deborah, "The word that saves Maastricht? The principle of subsidiarity and the division of powers within the European Community", en Common Market Law Review, 1992, p. 1110 y ss.; Ippolito, Fondamento, cit. nota n. 15. p. 1 y ss. 
El principio de subsidiariedad y su papel en la determinación de las competencias sancionatorias de la Unión Europea. Relación con el principio de complementariedad de la Corte Penal Internacional.

ejercicio de las mismas ${ }^{36}$, pues el propio Tratado de la Comunidad afirma que ésta deberá actuar dentro de los límites de las competencias que le atribuye el propio Tratado y de los objetivos que éste asigna. Por lo anterior, se desprende que el principio sólo deberá emplearse tratándose de las competencias compartidas, mas no de las exclusivas, pues respecto de estas últimas, se excluye toda actividad estatal. Que el principio legitime la actuación comunitaria respecto de las compartidas no constituye un título atributivo de las mismas, sólo supone como ya se señaló- un medio de regulación para su ejercicio. Si bien, en estricto rigor, los Estados siguen manteniendo la titularidad competencial, y que éstas no pasarán a ser exclusivas, mientras la Comunidad Europea continúe con su actividad interventora, aquellos estarán inhibidos de actuar. Con lo cual, en la práctica se podría generar una situación similar a que si se tratara de las exclusivas.

Para determinar si la Comunidad Europea puede actuar dentro de un determinado ámbito, debe examinarse, primeramente, si éste corresponde a los objetivos trazados por el propio Tratado, para posteriormente resolver con qué competencias cuenta para ello. Pues bien, una vez superada esta primera interrogante, corresponde preguntarse, si aún teniendo competencia la Comunidad para emprender una determinada acción, no resulta más adecuado que ésta sea realizada por los propios Estados miembros. Las instituciones europeas deberán valorar, conforme al principio de subsidiariedad, no sólo si su actuación resultará más oportuna, conforme a criterios de insuficiencia de la acción estatal y de eficacia comunitaria, sino también que ésta se halla justificada en razón de la envergadura e importancia que a nivel supranacional pueda tener el problema y su solución ${ }^{37}$, como se puede desprender del art. 5 ya citado. En todo caso, la actuación comunitaria no debe interpretarse en clave reduccionista ${ }^{38}$, es decir, que la Comunidad sólo actuará cuando los Estados lo hagan de manera insatisfactoria. Por el contrario, ésta debe hacerse de manera funcional, los organismos europeos siempre tendrán la potestad para actuar, en la medida que concurran los presupuestos mencionados. Concebido así el principio en cuestión, se adecua de manera más satisfactoria a la naturaleza expansiva que

36 Strozzi, Girolamo, "Le principe de subsidiarité dans le perspective de l'intégration européenne: una énigme et beaucoup d'attentes", en Revue Trimestrielle de Droit Européen, 1994, p. 380; Comisión de las Comunidades Europeas, Boletín de las Comunidades Europeas, n 10, Bruxelles, 1992, p. 118.

37 Boixareu, "El principio", cit. nota n. 35, p. 782; Isaac, Manual, cit. nota n. 19, p. 57; Comisión de las Comunidades Europeas, Boletín de las Comunidades Europeas, n 10, Bruxelles, 1992, p. 118: "Corresponde a las instituciones comunitarias la carga de la prueba de la necesidad de legislar y de actuar a nivel comunitario y con la intensidad propuesta".

38 Precisamente, dado el importante alcance que puede tener este principio en el desarrollo comunitario, y considerando la esencia federalista que subyace en él, no sería extraño observar entre quienes propugnan una Unión Europea de alcances más bien limitados, una interpretación restrictiva, de un perfil "descendente". Boixareu, "El principio", cit. nota n. 35, p. 787, indica —al examinar dicha posición— que lo que se propugna es una intervención "desde abajo” y por tanto, la comunitaria debe ser excepcional. 
caracteriza a la integración comunitaria, pues otorga una mayor operatividad $-\mathrm{y}$ por ende dinamismo ${ }^{39}$ - a la tarea comunitaria.

Podría pensarse que concebido el principio en esos términos, llevaría a una centralización decisoria en el ámbito comunitario. Estimo que no, pues el principio constituye una condición de actuación, la Comunidad deberá demostrar que concurren los requisitos exigidos para poder actuar y la relevancia que tiene su tratamiento en el campo supranacional. El principio de subsidiariedad se convierte así en instrumento de legitimación, que también supondrá impedir actuaciones injustificadas de la Comunidad ${ }^{40}$. Además, hay que tener presente —en la evitación de posibles interpretaciones abusivas - el control que puede ejercer el Tribunal de Justicia de las Comunidades Europeas ${ }^{41}$.

En cuanto al principio de proporcionalidad, si bien hoy se encuentra expresamente consagrado en el art. 5 inciso final, desde siempre ha sido reconocido por la jurisprudencia del Tribunal de Justicia de las Comunidades ${ }^{42}$. Fundamentalmente, se refiere a la naturaleza de la intervención comunitaria, esto es, a la obligación de verificar si los medios con los que pretende actuar son los adecuados para el logro de su objetivo y si éstos no exceden de lo necesario para lograrlo ${ }^{43}$. Mientras en sede de subsidiariedad lo que cabe es preguntarse si las entidades europeas pueden actuar, aquí la cuestión dice relación con la intensidad de tal intervención ${ }^{44}$.

39 No cabe duda que para la aplicación del principio también deben valorarse circunstancias espacio-temporales que justifiquen su invocación.

$40 \quad$ Para Barnés, "El principio”, cit. nota n. 34, p. 551: “...el poder comunitario se somete a un instrumento más de racionalidad, aunque, a la postre, podrá permitirle a la Comunidad actuar revestida de autoridad — cargada de razón- en campos y sectores en los que su intervención era menor o impensable hace no mucho tiempo".

41 En todo caso, la justiciabilidad del principio ha sido cuestionada por algunos. Al respecto, Ippolito, Fondamento, cit. nota n. 15, p. 225 y ss.; Barnés, "El principio", cit. nota n. 34, p. 546-548; Cass, "The word that saves", cit. nota n. 35, p. 1133.

42 Schwarze, Jürgen, European Administrative Law. London, 1992, p. 677 y ss., lo describe como el principio general del Derecho comunitario más importante. Este autor hace un estudio pomenorizado del alcance de la proporcionalidad, tanto en los sistemas jurídicos estatales como en la jurisprudencia del Tribunal de Justicia de las Comunidades Europeas (TJCE). Al respecto, es preciso destacar que distintos Tribunales constitucionales europeos lo han reconocido, aunque no haya tenido un respaldo normativo en sus ordenamientos jurídicos.

43 Así, entre otras, Sentencia TJCE Reino Unido c. Consejo de la Unión Europea, de 12 de noviembre de 1996, asunto C-84/94, Recopilación 1996-11; Sentencia TJCE República Federal de Alemania c. Parlamento Europeo y Consejo de la Unión Europea, de 13 de mayo de 1997, asunto C-233/94, Recopilación 1997-5.

44 Así lo entiende la Comisión de las Comunidades Europeas, Boletín de las Comunidades Europeas, $\mathrm{n}^{\circ} 10$, Bruxelles, 1992, p. 121-122, aunque incurre en confusión, al concebir la proporcionalidad como una de las dimensiones de la subsidiariedad; Barnés, "El principio", cit. nota n. 34, p. 554-555, en n. 108 al distinguir ambos principios señala: "Mientras la proporcionalidad mira a la adecuación de los medios a un fin determinado, la subsidiariedad examina a la legitimidad misma del fin. El primero es de carácter formal, puesto que se centra en la relación medio-fin; el segundo exige una decisión básica interna, de ahí que se requiera una concreción normativa para su aplicación al caso concreto. Es más ratio legis que lex, mientras que la proporcionalidad resulta aplicable y goza de un carácter normativo pleno". 
El principio de subsidiariedad y su papel en la determinación de las competencias sancionatorias de la Unión Europea. Relación con el principio de complementariedad de la Corte Penal Internacional.

En efecto, dentro de esta esfera ya se presupone que la acción comunitaria es válida — sean competencias exclusivas o compartidas, pues el art. 5 no distingue- lo que corresponde ahora, es precisar que las modalidades que se empleen no sean excesivas, considerando el resultado que se pretende obtener. Pues bien, conforme a lo anterior, la Comunidad debe optar —en la medida en que existan varios modos de acción- por aquel que, siendo igualmente efectivo, otorgue más libertad a los Estados, particulares o empresas.

\section{Competencia sancionatoria de las instituciones comunitarias}

En términos amplios, puede afirmarse que las Comunidades sí cuentan con competencias punitivas, si entendemos el ius puniendi en sentido amplio, es decir, comprendiendo en él las sanciones de naturaleza administrativa. Como se expuso supra, las Comunidades son fundamentalmente una organización que goza de competencias de atribución, es decir, sólo pueden actuar en aquellos ámbitos que han sido cedidos por los Estados. No obstante, considerando que lo que se atribuye no son materias, sino objetivos a lograr, dada la orientación funcionalista que marca el proceso comunitario, nada impediría estimar las medidas sancionatorias — sin entrar todavía a precisar su naturaleza — como un instrumento que permitan alcanzar las metas propuestas para el proceso integrador. Según mi parecer, ello no significa exceder los márgenes competenciales, por el contrario, permite a la Comunidad cumplir los mandatos propuestos, al contar con los elementos necesarios para reaccionar ante las infracciones a sus propias normas. Sería extraño pensar que se atribuyen a la entidad europea la consecución de determinados fines y no pueda disponer para ello de todos los instrumentos que son necesarios para tutelar, precisamente, los bienes jurídicos que surgen de las actividades comunitarias. En la medida en que se confiere a la Comunidad Europea facultades sobre determinados ámbitos, en ellas deben entenderse incluidas la introducción de medidas sancionatorias ${ }^{45}$. Precisamente, una manifestación clara de lo que se acaba de exponer - y que se halla refrendado por el propio Tribunal de Justicia de las Comunidades ${ }^{46}$ — son las sanciones comunitarias indirectas que se han desarrollado en la esfera de la Política Agrícola Común. En efecto, sin que exista una disposición expresa que autorice la introducción de medidas sancionatorias, se ha interpretado que cuando el art. 34. 2 del Tratado de la Comunidad señala que deben aplicarse "todas las medidas necesarias para alcanzar los objetivos", se entienden entre ellas, las disposiciones sancionatorias ${ }^{47}$. Lo expuesto constituiría una demostración del desarrollo de las competencias implícitas ${ }^{48}$, que tan importante impulso ha brindado al proceso de integración, y que ahora se refleja en una esfera tan delicada como las sancionatorias.

45 Al respecto, cfr. Vilá Costa, Blanca, "El régimen jurídico de las sanciones por infracciones a normas comunitarias", en Revista de Instituciones Europeas, 1991, p. 821.

Sentencia TJCE Alemania c. Comisión de 27 de octubre de 1992, asunto C-240/90, Recopilación 1992-8.

Así, Riondato, Silvio, Competenza penale della Comunità europea. Padova, 1996, p. 57.

Éstas encuentran su basamento, fundamentalmente, en la teoría de los poderes implícitos —surgida en la jurisprudencia norteamericana-. Grosso modo, supone la asunción de determinadas competencias que, aunque 
Se suele señalar como límite a la conformación de una competencia sancionadora europea, el principio de subsidiariedad, consagrado en el art. 5 del Tratado de la Comunidad, en cuanto a que sólo en forma excepcional debe recaer en los entes supranacionales, debiendo corresponder - por regla general - a los Estados miembros la sanción de las infracciones al Derecho Comunitario. Es decir, aunque buena parte de los bienes jurídicos queden configurados por el ordenamiento comunitario, su protección debe quedar en manos de los países miembros. Lo que podría sí realizar la Comunidad es la armonización o coordinación de los derechos sancionadores nacionales. Si bien lo expuesto, en términos generales, es correcto, creo que el principio en cuestión más que constituir una limitación puede servir, precisamente, de apoyo normativo para una injerencia en este campo por parte de la Comunidad Europea. En efecto, cuando se examinó la subsidiariedad se hizo especial hincapié sobre la necesidad que existe, para su invocación, de valorar no sólo si una actuación comunitaria resulta oportuna — conforme a criterios de insuficiencia estatal y de eficacia comunitaria - sino también, si ésta se justifica dada la envergadura e importancia que el problema y su solución tienen en el ámbito comunitario. Concurriendo estas circunstancias, el principio se transforma en un instrumento de justificación de la acción comunitaria. Por tanto, teniendo presente estas consideraciones, como la constatación de que efectivamente existe un inadecuado tratamiento punitivo de los intereses comunitarios, me parece que el principio de subsidiariedad no puede verse como una limitación de la acción comunitaria, por el contrario, puede servir precisamente, de justificación para su intervención ${ }^{49}$. De entenderse este principio en un sentido demasiado restrictivo, se estaría privando incorrectamente a la Comunidad de un instrumento de actuación en este ámbito.

Si bien puede quedar claro que se dispone en el ámbito comunitario de competencias para imponer sanciones administrativas, cabe la pregunta si es posible introducir sanciones de naturaleza penal. Esto es, si las instituciones comunitarias disponen de competencias para

no estén previstas en los Tratados, se estiman indispensables para poder efectivamente cumplir con aquéllas que sí le han sido atribuidas. El Tribunal de Justicia de las Comunidades, apoyándose en esta teoría — que ya era aceptada para los organismos internacionales-, pero siguiendo líneas interpretativas más amplias, ha permitido fundamentar la realización de determinadas políticas, lo que ha supuesto una extensión de las competencias atribuidas a la Comunidad Europea. Eso sí, la competencia implícita, surgida de la interpretación jurisprudencial, debe cimentarse en alguna norma expresa de los Tratados. Sin perjuicio de lo expuesto, el empleo de esta vía de actuación competencial ha sido más bien moderado, debido esencialmente, a los reparos que los Estados miembros puedan ofrecer ante lo que podría estimarse como un menoscabo de sus propias facultades. Lenaerts, Koen/Van Ypersele, Patrick, "Le principe de subsidiarité et son contexte: étude de l'article 3 B du Traité CE", en Cahiers de Droit Européen, 1994, p. 41, señalan que recurrir a las competencias implícitas se justifica si no existe una explícita y que deben motivarse conforme a los elementos objetivos suceptibles de control jurisdiccional, que establezcan una línea íntima entre la competencia implícita invocada y la explícita, de manera que la existencia de la primera condicione el efecto útil de la segunda. Fundamental, Sentencia TJCE AETR de 31 de marzo de 1971, as. 22/70, Rec. 1971.

49 Así, Bernardi, Alessandro, “ 'Europeizzazione' del Diritto penale commerciale?”, en Rivista Trimestrale di Diritto Penale dell'Economia, 1996, p. 37. 
El principio de subsidiariedad y su papel en la determinación de las competencias sancionatorias de la Unión Europea. Relación con el principio de complementariedad de la Corte Penal Internacional.

establecer un Derecho penal criminal. Se puede afirmar que la Comunidad carece de las competencias necesarias para imponer este género de sanciones en el ordenamiento comunitario, es decir, carece de facultades tanto respecto a la creación de tipos penales - Jurisdiction to prescribe - como para la imposición de sanciones penales — Jurisdiction to enforce — ${ }^{50}$. Lo anterior, en todo caso, no impide que igualmente la institucionalidad europea ejerza una enorme influencia sobre los Derechos penales nacionales, a través de las llamadas técnicas de asimilación o armonización ${ }^{51}$. Como asimismo, a través de los instrumentos propios del tercer pilar, que son de orden intergubernamental_Título VI del Tratado de la Unión Europea_. Precisamente, bajo este título es que se ha procurado materializar la protección de los intereses financieros comunitarios $^{52}$. Ello, sin perjuicio del recurso a los instrumentos comprendidos dentro del primer pilar, esto es, de la esfera comunitaria.

En todo caso, es importante señalar que la afirmación sobre la carencia de competencias penales de la Comunidad hoy se encuentra cuestionada por la sentencia del Tribunal de Justicia de las Comunidades de 13 de septiembre de 2005, causa C-176/03, por la cual se anuló, conforme al art. 35 del Tratado de la Unión Europea, una decisión marco del Consejo de 23 de enero de 2003, relativa a la protección del medioambiente a través del Derecho penal. El Tribunal sostuvo que existen bases jurídicas para tratarlo en el primer pilar, argumentando que no se puede impedir al legislador comunitario procurar la armonización de las legislaciones penales internas, cuando la aplicación de sanciones penales efectivas, proporcionales y disuasivas por parte de las autoridades nacionales constituye una medida indispensable para luchar contra la violación de las medidas ambientales ${ }^{53}$.

\section{Relación con el principio de complementariedad}

De lo expuesto se aprecia el papel fundamental que el principio de subsidiariedad desempeña en la determinación de las esferas competenciales entre los Estados miembros y

$50 \quad$ Al respecto, Consulich, Federico, “«Materia penale» e tutela dei beni giuridici nello spazio unitario europeo", en Rivista Trimestrale di Diritto Penale dell'Economia, 2006, p. 77; Bacigalupo, "Derecho penal”, cit. nota n. 11, p. 137 y ss., señala que el proyecto de Constitución europea otorgaba competencia penal a la Unión Europea.

51 Bernardi, Alessandro. L'Europeizzazione del Diritto e della scienza penale. Torino, 2004, p. 11 y ss.

$52 \quad$ Picotti, Lorenzo, "L'attuazione in Italia degli strumenti dell'Unione Europea per la protezione penale degli interessi finanziari comunitari”, en Rivista Trimestrale di Diritto Penale dell'Economia, 2006, p. 615 y ss.; Nieto Martín, Adán, Fraudes comunitarios. Barcelona, 1996, p. 369 y ss.; Gröblinghoff, Stefan. Die Verpflichtung des deutschen Strafgesetzgebers zum Schutz der Interessen der Europäischen Gemeinschaften. Heidelberg, 1996, p. 153 y ss.; Mezzetti, Enrico, La tutela penale degli interessi finanziari dell'Unione Europea. Padova, 1994, p. 19 y ss.

53 Mannozzi, Grazia/Consulich, Federico, "La sentenza della Corte di Giustizia C-176/03: riflessi penalistici in tema di principio di legalità e politica dei beni giuridici”, en Rivista Trimestrale di Diritto Penale dell'Economia, 2006, p. 899 y ss.; Estrada Cuadras, Albert, "Vía libre al Derecho penal europeo", en InDret 2/2006, p.1-18 (www.indret.com) (consultado el 7 de abril de 2009). 
las instituciones europeas. En este sentido, no es extraño afirmar que el principio de complementariedad juega un papel similar en el marco de la Corte Penal Internacional, pues también pretende buscar los necesarios equilibrios entre las jurisdicciones nacionales, destacando las ventajas que éstas representan en la solución del conflicto, pero precisando cuándo se hace necesaria la intervención internacional ${ }^{54}$. Sin embargo, como se verá se presentan importantes diferencias que no es posible soslayar.

La primera y más elemental distinción se presenta en que la Corte -como se precisa ya desde su preámbulo- sólo tiene un carácter complementario de las jurisdicciones nacionales. Es decir, los actores principales llamados a juzgar a los responsables por crímenes internacionales, son los Estados y sólo cuando éstos no puedan o no desean hacerlo podrá intervenir la Corte Penal Internacional -art. 17 del Estatuto-. Por tanto, en este contexto y a diferencia de lo que sucede en la esfera de la Unión Europea, no se está frente a competencias exclusivas o compartidas, sino que la competencia primaria la tienen los Estados ${ }^{55}$. En todo caso, aun cuando son los Estados los primeros llamados a juzgar crímenes internacionales, no se puede en rigor hablar de primacía de la jurisdicción estatal por sobre la internacional, pues, como se expondrá infra, es la propia Corte la que decide cuándo puede actuar y no los Estados ${ }^{56}$. Asimismo, a pesar de que se cuestiona el término complementariedad y hay quienes prefieren hablar de la subsidiariedad de la Corte Penal, parece necesario mantener tal noción. En efecto, aun cuando las facultades jurisdiccionales de los Estados se mantienen inalteradas, éstas se complementan con las de la Corte, lo que supone un mejoramiento en el sistema de persecución de ciertos crímenes internacionales. De tal manera que si eventualmente actúa la Corte lo hace con la cooperación de los Estados, obligados al haberse comprometido a través de la ratificación del Estatuto de Roma ${ }^{57}$. Se está frente a un complemento y no ante una cesión de competencias, como sí acontece en la Unión Europea por aplicación del principio de subsidiariedad.

Tratándose de los Tribunales Penales Internacionales para la ex Yugoslavia y para Ruanda, la primacía, conforme se dispone en sus Estatutos -art. 9 y 8 respectivamente-, la tienen éstos por sobre cualquier tribunal nacional. En cambio, respecto de la Corte Especial para Sierra Leona y el Tribunal Especial para El Líbano su primacía es sólo sobre sus propias cortes.

\footnotetext{
$54 \quad$ Miskowiak, The International, cit. nota n. 10, p. 45. Para conocer el desarrollo del principio de complementariedad, El Zeidy, Mohamed M, The principle of Complementarity in International Criminal Law. Leiden-Boston, 2008, p. 11 y ss. expone exhaustivamente el desarrollo del principio desde 1919; Stigen, Jo, The relationship between the International Criminal Court and National Jurisdictions. The Principle of Complementarity. Leiden, 2008, p. 31 y ss.; Williams, Sharon A./Schabas, William A., "Article 17", en: Triffterer, Otto, Commentary on the Rome Statute of the International Criminal Court. $2^{\circ}$ ed. München, 2008, p. 607 y ss.

55 Williams/Schabas, "Article 17", cit. nota n. 54, p. 606.

56 Cárdenas Aravena, Claudia, "La Corte Penal Internacional y su relación con las jurisdicciones nacionales", en Revista del Magíster y Doctorado en Derecho, № 1, 2007, p. 127, n. 12.

57

Cárdenas, "La Corte Penal", cit. nota n. 56, p. 129.
} 
El principio de subsidiariedad y su papel en la determinación de las competencias sancionatorias de la Unión Europea. Relación con el principio de complementariedad de la Corte Penal Internacional.

Algunas de las razones esgrimidas para ello fue evitar la cultura de la impunidad que podría haber tenido lugar, debido a las serias dificultades de funcionamiento de las instituciones nacionales. Asimismo, como sucedió con el gobierno ruandés, la instalación de tribunales en lugares geográficamente distantes, permitía una mayor imparcialidad y justicia ${ }^{58}$.

Como resulta evidente, la naturaleza política de la Corte no tiene un carácter funcional -conforme se explicó supra- y por tanto, no existe un riesgo expansivo a costa de las competencias estatales. Por el contrario, el éxito de la Corte radica en que los Estados puedan ejercer debidamente su jurisdicción, de manera que la Corte pueda concentrar sus esfuerzos en aquellos casos en que se presente un peligro real de impunidad, que en la mayoría de los casos es fáctica y no normativa ${ }^{59}$. Pensar que la Corte pueda tener primacía por sobre las instituciones nacionales, como se dispone respecto de los tribunales ad hoc, la destinaría al fracaso, pues no podría cumplir adecuadamente su misión ${ }^{60}$. Y es que deben tenerse presente razones prácticas que se derivan del principio de territorialidad, pues son las normas nacionales las que tienen una mayor eficacia preventivo general. Además, son las instituciones nacionales las que tienen mayor capacidad operativa para realizar una mejor tarea investigativa ${ }^{61}$.

Además, y sin perjuicio de lo expuesto, no pueden dejarse de lado aquellas razones que provienen del celo soberano de los Estados, que desaconsejan dotar al ente internacional de primacía por sobre los Estados. Y es que como se hizo notar supra respecto de la Unión Europea, en esta esfera los Estados aprecian el ejercicio del ius puniendi como sinónimo de una de las manifestaciones más evidentes del poder soberano estatal ${ }^{62}$. Unido a lo anterior, en no pocos casos los crímenes internacionales son cometidos por agentes del Estado amparados por sus

58 Tiefenbrun, Susan W., "The paradox of International adjudication: developments in the International Criminal Court for the Former Yugoslavia and Rwanda, the World Court and the International Criminal Court", en North Carolina Journal of International Law and commercial regulation, $\mathrm{N}^{\circ} 3,2000$, p. 563 y ss. ; Zahar, Alexander/ Sluiter, Göran, International Criminal Court. New York, 2008, p. 450-454 ; Cassese, International, cit. nota n. 6, p. 339-342; El Zeidy, The principle, cit. nota n. 54, p. 137-139.

59 Como destaca Ambos, La parte general, cit. nota n. 9, p. 33, generalmente la impunidad no se debe a lagunas jurídicas por falta de tipos penales, sino al escaso interés en la persecución por parte de los Estados.

60 Cassese, International, cit. nota n. 6, p. 336-339; Miskowiak, The International, cit. nota n. 10, p. 41; Lindemann, Jürg, "El significado de la Corte Penal Internacional bajo la especial consideración de la controversia sobre la jurisdicción universal”. (trad. A. Espinosa e I. Álvarez), en Revista de Estudios de la Justicia, N 4, 2004, p. 96.

61 Carnevali, "Hacia la conformación”, cit. nota n. 6, p. 32; Cerezo Mir, José, Curso de Derecho penal español. T. I. $5^{\circ}$ ed. Madrid, 1996, p. 194.

62 Sin ir más lejos, una de las razones esgrimidas por la sentencia del Tribunal Constitucional chileno de 8 de abril de 2002 dice relación con la disminución de la soberanía (Considerando 51): "El Tribunal creado por el Estatuto, en la categoría a la que se deba adecuar, no se encuentra directa o indirectamente previsto o admitido por el texto constitucional y la esfera jurisdiccional que le es atribuida verá reducir, correlativamente, la dimensión de soberanía constitucional deferida a los tribunales. Con el Estatuto, la competencia soberana que es una jurisdicción constituida resultará necesariamente disminuida, por la transferencia para el Tribunal de una de sus atribuciones."; Cfr. Correa G., Rodrigo/Bascuñán Rodríguez, Antonio, "El estatuto de Roma ante el Tribunal Constitucional chileno", en Revista de Estudios de la Justicia, N 1, 2002, p. 129 y ss.; Guzmán Dalbora, José Luis, "Informe 
propias autoridades ${ }^{63}$. De tal manera, que aparece como una medida prudente, de estabilidad social, que sea el propio Estado el que procure real y efectivamente buscar mecanismos de solución de conflictos.

Debe hacerse presente que, a diferencia de lo que ocurre en el ámbito europeo, los Estados no ceden su competencia, en este caso la penal. Por tanto, los temores en este sentido son infundados. El principio de complementariedad regulado en el art. 17 del Estatuto dispone de criterios para resolver cuestiones de admisibilidad, siendo la Corte la que primero debe pronunciarse sobre la competencia ${ }^{64}$.

No obstante, ser los Estados nacionales los primeros llamados a resolver, la competencia de la Corte se precisa en el mismo Estatuto. En efecto, ésta se delimita sobre la base de ciertos criterios: a) la esfera de delitos que puede conocer -ratione materiae- en el art. 5; b) momento de la comisión -ratione temporis_en el art. 11; c) lugar de los hechos -ratione loci-y nacionalidad del acusado -rationae persona- en el art. 12. Asimismo, el Estatuto se hace cargo de cuestiones de orden procedimental y orgánico ${ }^{65}$.

Por tanto, el marco de actuación de la Corte se encuentra previamente circunscrito y no puede excederse, lo que lo distingue claramente de las instituciones comunitarias europeas. Otra cosa es, empero, resolver cuándo puede actuar, y es aquí donde juega un papel esencial el principio de complementariedad ${ }^{66}$.

Como se ha podido vislumbrar de lo expuesto, el art. 17 resuelve la admisibilidad de la intervención de la Corte. Prima facie, y amén de la gravedad que los hechos deben revestir, puede decirse que los criterios son bastantes restrictivos y se limitan esencialmente -no exclusivamente- a dos supuestos, a saber, que el Estado no pueda o no desea ejercer su jurisdicción ${ }^{67}$. Precisamente, el art. 17. 2 expone las circunstancias que permiten valorar la

sobre Chile", en Ambos, Kai/Malarino, Ezequiel/Woischnik, Jan, Dificultades jurídicas y políticas para la ratificación o implementación del Estatuto de Roma de la Corte Penal Internacional. Montevideo, 2006, p. 176 y ss.; Gamboa, Fernando, "El fallo del Tribunal Constitucional sobre la constitucionalidad o inconstitucionalidad del tratado que crea el Tribunal Penal Internacional", en Actualidad Jurídica, Universidad del Desarrollo. 2002, $\mathrm{N}^{\circ}$ 6, p. 155 y ss.; Bruna, Guillermo, "Algunas consideraciones sobre la constitucionalidad de la Corte Penal Internacional", en Ius et Praxis, año 6, N 2, 2000, p. 435 y ss.; Mohor Abuauad, Salvador/Varas Alfonso, Paulino, "Corte Penal Internacional: evaluación crítica y cuestiones constitucionales", en Temas de Derecho, Universidad Gabriela Mistral, año XV, N 1 y 2, 2000, p. 97 y ss.; Rojas Sepúlveda, Mario, "Corte Penal Internacional y Soberanía Universal”, en Actualidad Jurídica, Universidad del Desarrollo, N², 2000, p. 9 y ss. 63 Stigen, The relationship, cit. nota n. 54, p. 39.

64 Lindemann, "El significado", cit. nota n. 60, p. 96.

65 Como señalan Correa/Bascuñán, "El estatuto", cit. nota n. 62, p. 130, el Estatuto es una mixtura entre Código penal, Código Procesal Penal y Código Orgánico de Tribunales.

66 El Zeidy, The principle, cit. nota n. 54, p. 157 y ss.

67 Sobre la discusiones que al respecto tuvieron lugar en la Sala de Cuestiones Preliminares (Pre Trial Chamber) por el caso Lubanga, Williams/Schabas, "Article 17”, cit. nota n. 54, p. 615-616; sobre la situación en Darfur y la ausencia de procedimientos criminales por parte de la justicia sudanesa, Schabas, An Introdution, cit. nota n. 6, p. 176-177 
El principio de subsidiariedad y su papel en la determinación de las competencias sancionatorias de la Unión Europea. Relación con el principio de complementariedad de la Corte Penal Internacional.

concurrencia de éstos ${ }^{68}$. Por tanto, la Corte puede intervenir ya sea que el Estado no ha ejercido su jurisdicción o de haberlo hecho no se aprecia una voluntad real de justicia. Es más, la Corte puede decidir actuar aun cuando haya recaído sobre una causa el efecto de cosa juzgada -art. 20. 3-. Es decir, aunque se reconozca la autoridad que impone la litis pendentia y la cosa juzgada para desautorizar la competencia de la Corte, se disponen excepciones ${ }^{69}$.

Justamente, una de las mayores críticas que se han dirigido en contra del principio en comento es que sea la propia Corte la que resuelva la admisibilidad, pero no parece viable otro mecanismo resolutivo. Y es que la experiencia histórica ha demostrado que buena parte de los actos que infligen los Derechos fundamentales tienen lugar dentro de un conflicto interno y son ejecutados por los propios agentes del Estado o amparados por éste. En consecuencia, es de toda justicia que ante la eventual pasividad con que puedan obrar las autoridades nacionales, se pueda contar con otras instancias ${ }^{70}$.

En todo caso, que sea una instancia internacional la encargada de resolver cuestiones de admisibilidad de alguna forma "obligará" a los Estados a adecuar sus ordenamientos e implementar el Derecho Penal Internacional, si efectivamente pretenden mantener su preeminencia por sobre la Corte Penal ${ }^{71}$. En este sentido, se puede producir un fenómeno similar al acontecido en la Unión Europea en la conformación del Derecho Sancionador Comunitario. Y es que la jurisprudencia del Tribunal de Luxemburgo favorece una aproximación de los ordenamientos nacionales, a través de una "circulación" de los principios jurídicos de algunos Estados miembros dentro del ordenamiento comunitario, para que después, éstos sean traspasados a otros Estados miembros ${ }^{72}$. Precisamente, el desarrollo jurisprudencial de la Corte Penal Internacional repercutirá en los Estados nacionales, reforzando su actuación frente a los crímenes internacionales ${ }^{73}$.

Para Morris, Madeline, "Complementarity and its discontents: States, Victims, and the International Criminal Court", en Shelton, Dinah, International crimes, peace, and human rights: The role of the International Criminal Court. Ardsley, NY, 2000, p. 193, la complementariedad incorpora indicios propios de la primacía ejercida por el Tribunal penal para la ex Yugoslavia, al dejar que sea la propia Corte la que determine su admisibilidad. Penagos Trujillo, Sandra/Sánchez Posso, Juan Carlos, El non bis in idem y la cosa juzgada en el Estatuto de Roma de la Corte Penal Internacional. Bogotá, 2007, p. 145 y ss.

70 En este sentido, Troncoso Repetto, Claudio., "La Corte Penal Internacional y el principio de la complementariedad", en Ius et Praxis, año 6, N², 2000, p. 413.

71 Ambos, Kai/Woischnik, Jan (Ed.), Dificultades jurídicas y políticas para la ratificación o implementación del Estatuto de Roma de la Corte Penal Internacional. Contribuciones de América Latina y Alemania. Montevideo, 2006; Cárdenas A., Claudia. "Los crímenes del Estatuto de la Corte Penal Internacional en el derecho chileno, necesidad de una implementación”, en Política Criminal. № 2, A1, 2006, p. 1-17 (www.politicacriminal.cl) (consultado el 3 de febrero de 2009).

72 En estos términos, Adinolfi, Adelina, "I principi generali nella giurisprudenza comunitaria e la loro influenza sugli ordinamenti degli Stati membri”, en Rivista Italiana di Diritto Publico Comunitario, 1994, p. 524, p. 563. 